\title{
Dual role of TRBP in HIV replication and RNA interference: viral diversion of a cellular pathway or evasion from antiviral immunity? Anne Gatignol*, Sébastien Lainé and Guerline Clerzius
}

\author{
Address: Virus-Cell Interactions Laboratory, Lady Davis Institute for Medical Research, and Department of Medicine and Microbiology \& \\ Immunology, McGill University, Montréal, Québec, Canada \\ Email: Anne Gatignol* - anne.gatignol@mcgill.ca; Sébastien Lainé - sebastienlaine@hotmail.com; Guerline Clerzius - gclerzius@yahoo.ca \\ * Corresponding author
}

Published: 27 October 2005

Retrovirology 2005, 2:65 doi:10.1186/1742-4690-2-65

This article is available from: http://www.retrovirology.com/content/2/1/65

(c) 2005 Gatignol et al; licensee BioMed Central Ltd.

This is an Open Access article distributed under the terms of the Creative Commons Attribution License (http://creativecommons.org/licenses/by/2.0), which permits unrestricted use, distribution, and reproduction in any medium, provided the original work is properly cited.

\begin{abstract}
Increasing evidence indicates that RNA interference (RNAi) may be used to provide antiviral immunity in mammalian cells. Human micro (mi)RNAs can inhibit the replication of a primate virus, whereas a virally-encoded miRNA from HIV inhibits its own replication. Indirect proof comes from RNAi suppressors encoded by mammalian viruses. Influenza NSI and Vaccinia E3L proteins can inhibit RNAi in plants, insects and worms. HIV-I Tat protein and Adenovirus VA RNAs act as RNAi suppressors in mammalian cells. Surprisingly, many RNAi suppressors are also inhibitors of the interferon (IFN)-induced protein kinase R (PKR) but the potential overlap between the RNAi and the IFN pathways remains to be determined. The link between RNAi as an immune response and the IFN pathway may be formed by a cellular protein, TRBP, which has a dual role in HIV replication and RNAi. TRBP has been isolated as an HIV-I TAR RNA binding protein that increases HIV expression and replication by inhibiting PKR and by increasing translation of structured RNAs. A recent report published in the Journal of Virology shows that the poor replication of HIV in astrocytes is mainly due to a heightened PKR response that can be overcome by supplying TRBP exogenously. In two recent papers published in Nature and EMBO Reports, TRBP is now shown to interact with Dicer and to be required for RNAi mediated by small interfering (si) and micro (mi)RNAs. The apparent discrepancy between TRBP requirement in RNAi and in HIV replication opens the hypotheses that RNAi may be beneficial for HIV-I replication or that HIV-I may evade the RNAi restriction by diverting TRBP from Dicer and use it for its own benefit.
\end{abstract}

RNA interference (RNAi) is a natural antiviral mechanism in plant and insect cells. It can also be induced by mammalian and insect viruses in Caenorhabditis elegans, although there is no worm-specific virus isolated so far. An increasing number of observations indicate that RNAi may also be used by mammalian cells to counteract virus infection as a natural innate immunity [1-6]. A large number of mammalian viruses have been downregulated in vitro and in vivo by RNAi using exogenous small interfering (si)-, short hairpin (sh)- or micro (mi)- RNAs, showing that mammalian cells have the potential to mediate RNAi and to inhibit viruses by this mechanism $[7,8]$. In addition to cytokine production and the interferon (IFN) response, higher eukaryotes may have developed the RNAi mechanism as an additional innate immune response to pathogen infection. Alternatively, cells may have adapted this ancient mechanism required for developmental regulation as a response to prevent invasion by exogenous nucleic acids. 
Several pieces of evidence support the role of RNAi as an antiviral immune response in mammalian cells [5]. Viral miRNAs isolated from cells infected by Epstein-Barr virus (EBV) and HIV-1 constitute the first evidence of a role of the RNAi mechanism during viral infection [9,10]. Retroviruses provide another example showing that a cellular miRNA restricts the replication of the primate foamy virus PFV-1 in human cells [11]. Other indirect support for this hypothesis is the presence of virus-encoded RNAi suppressors. Influenza virus NS1 and vaccinia E3L proteins, two inhibitors of the IFN-induced protein kinase R (PKR), inhibit RNAi pathways in plants and in Drosophila cells [12]. HIV-1 Tat protein acts as an RNAi suppressor in the pathway mediated by shRNAs but not siRNAs, suggesting a specificity of action [10]. Adenovirus VA RNAI and VA RNAII are cleaved by Dicer and act as RNAi suppressors [13]. Both Tat protein and VA RNAs inhibit Dicer activity. A striking feature of RNAi suppressors characterized thus far from mammalian viruses is that most are also inhibitors of PKR, either by direct binding, by RNA sequestration or by substrate competition [14]. However, this feature is not shared by plant and insect silencing suppressors. This characteristic suggests a link or an overlap between the mechanism of RNAi and the PKR pathway in mammalian cells. One common feature is that both mechanisms are triggered by dsRNA, but three recent papers published in Nature, EMBO Reports and the Journal of Virology establish another link through a doublestranded (ds) cellular RNA binding protein, TRBP. TRBP binds Dicer and is part of the RNA-induced silencing complex (RISC), but it is also a strong inhibitor of PKR responsible for enhancement of HIV-1 replication [15-17].

TRBP was isolated as an HIV-1 trans-activation response (TAR) RNA binding protein that enhances virus expression $[18,19]$. It belongs to the family of dsRNA binding proteins with two dsRBDs and a KR-helix motif within dsRBD2 that mediates RNA binding. A third C-terminal basic domain does not mediate RNA binding [20,21]. TRBP is a strong PKR inhibitor by direct binding through its dsRBDs and by dsRNA sequestration [22-24]. TRBP also has a direct activity on translation independent of PKR but dependent on a structured RNA [25]. All assays done thus far with HIV show that the protein contributes positively to the enhancement of HIV-1 expression and replication (Fig. 1). A recent paper in the Journal of Virology further demonstrates this ability. In Ong et al., [17] published in the October 15 issue (chosen as a spotlight by the editors), the authors demonstrate that HIV-1 replicates poorly in astrocytes because of a heightened PKR response, that mediates poor translation of the viral structural proteins. They demonstrate that HIV replication can be rescued by expressing low amounts of the PKR inhibitor TRBP. In this context, TRBP prevents PKR activation, restores the production of viral proteins and consequently

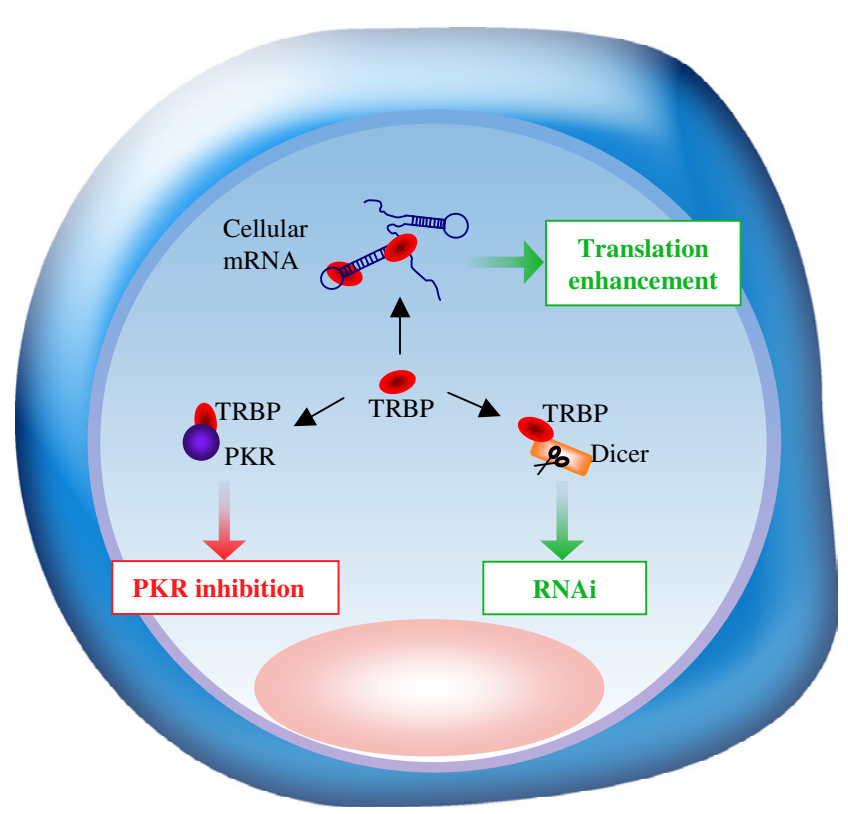

Figure I

TRBP acts in the cell by at least three different mechanisms: i) it enhances translation by binding to dsRNAs; ii) it binds to PKR and inhibits its function;iii) it participates to the RNAi pathway by interacting with Dicer.

HIV replication. The profound impact of TRBP transfection in these cells comes from its low endogenous expression due to a weak activity of TRBP promoter [26]. The low permissivity to HIV replication in astrocytes can therefore be ascribed in large part to low TRBP expression. This recent paper provides an additional mechanistic explanation for the low HIV replication in astrocytic cells and demonstrates the key role of TRBP in virus translation by counteracting the antiviral immunity mediated by PKR.

At the same time two papers published recently in Nature and EMBO Reports show that TRBP binds Dicer, that it is part of RISC, and that it is required for RNAi in human cells $[15,16]$. In both papers, the authors isolated ribonucleoprotein complexes containing Dicer, analyzed them by gel electrophoresis and mass spectrometry. Argonaute 2 (Ago2) and TRBP were among the proteins found reproducibly in the complex. The interaction between TRBP and Dicer was confirmed by immunoprecipitation and in vitro interaction. Haase et al., show that the interaction is independent from RNA and that the complex cofractionates with the miRNA miR-17. By using a two-hybrid assay, they map the interaction to the C-terminal domain in TRBP, which is devoid of RNA binding activity, providing further evidence of a direct interaction between the two 

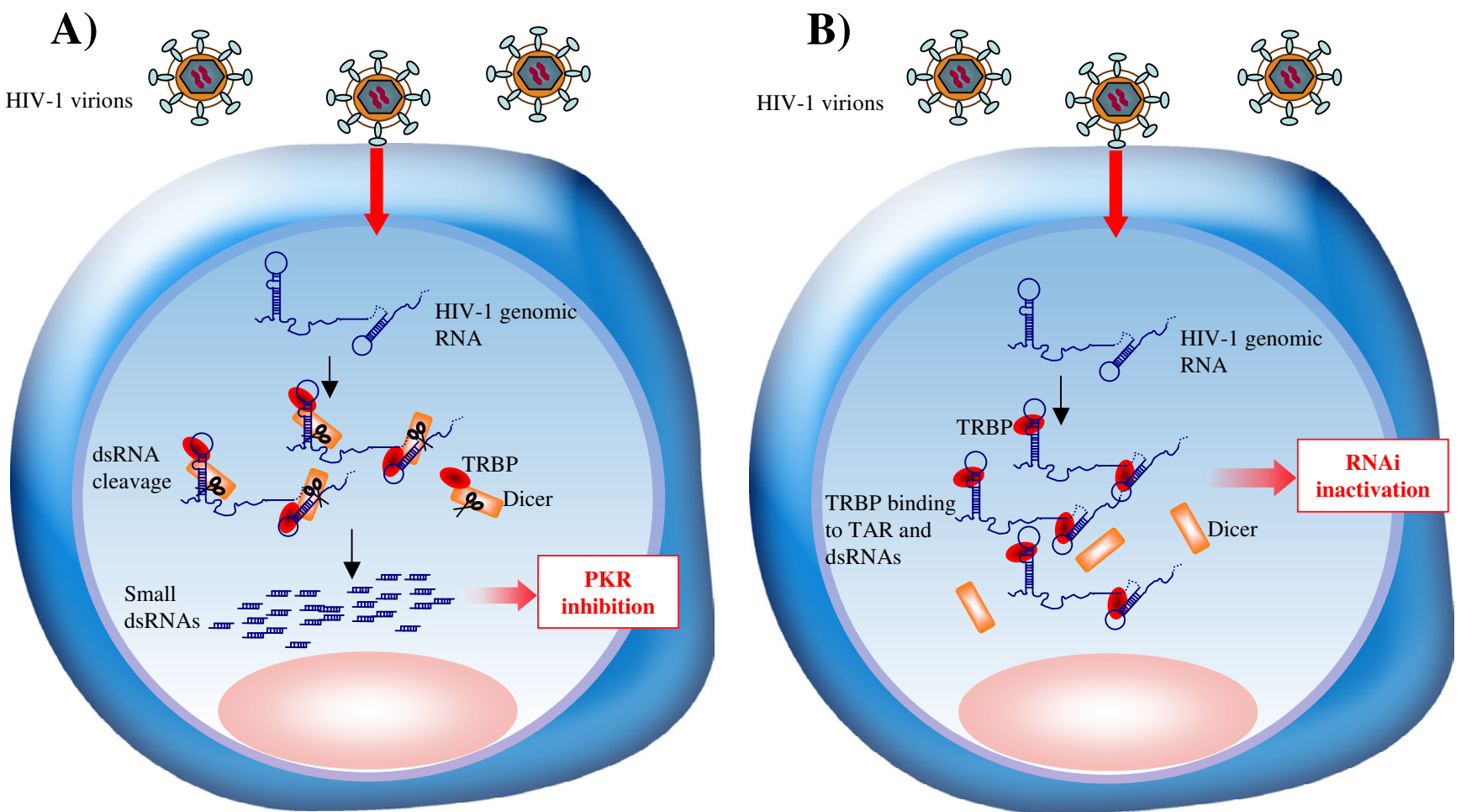

\section{Figure 2}

Model for the role of TRBP during the early steps of viral infection. A) HIV co-opts the RNAi pathway for its own benefit. After the uncoating steps, the viral RNA is released in the cytoplasm. The TRBP-Dicer complex binds to viral and cellular RNAs and cleaves small dsRNAs that inhibit PKR. B) HIV diverts TRBP from Dicer to avoid the cleavage of its RNA. The viral RNA released in the cytoplasm binds TRBP, which becomes unavailable for interaction with Dicer. The schematic representation of HIV-I genomic RNA includes the 5' and 3' TAR RNAs, the RRE RNA, the vsiRNA and other potential stem-loop structures.

proteins. Chendrimada et al., show that TRBP forms ribonucleoprotein complexes composed of [siRNA-TRBPDicer-Ago2], indicating that TRBP appears as the bridge between dsRNA and Dicer for Ago2 recruitment. Using siRNAs against either TRBP or Dicer and subsequent immunoprecipitation of Ago2, the authors show a decrease in both TRBP and Dicer concluding to a loss of stability of the reciprocal partner. However, this decrease rather indicates that Ago2 requires both proteins to effectively bind the complex. Using the same siRNAs, they further show a decrease in mature miRNA production and a loss of siRNA function either after TRBP or after Dicer depletion. They conclude that TRBP recruits Ago2 to RISC and that it couples the initiation and the execution steps of RNAi. Haase et al., show that in vitro processing, but not in vivo steady-state levels of miRNAs, is decreased by TRBP depletion. SiRNAs against TRBP did not cause destabilization of Dicer, but decreased the efficiency of RNAi mediated either by miR17 or by an anti-lamin siRNA, indicating that TRBP is involved in both processes. The conclusion of both papers is that TRBP is a partner of Dicer that is required for siRNA as well as miRNA function in human cells.

Considering that TRBP is required both for RNAi and for an efficient HIV replication, it is difficult to understand how RNAi could function as a cellular antiviral mechanism against HIV. In this regard, two possibilities arise: 1) Instead of mediating antiviral immunity, RNAi could be beneficial for the virus and 2) HIV may divert TRBP and use it for its own benefit to avoid RNAi cleavage.

1) Could HIV replication benefit from the RNAi pathway? Because RNAi is a mechanism that cleaves RNAs homologous to defined siRNAs, it should participate to the elimination of unwanted exogenous RNA to protect the cell. However, numerous examples show that viruses also coopt cellular pathways and use them for their own replica- 
tion [14]. Therefore, we cannot exclude that the RNAi pathway can support HIV replication and possibly other viruses. Indeed, one recent study shows that a liver-specific miRNA, miR-122, facilitates hepatitis $\mathrm{C}$ virus (HCV) replication, although in this case, the virus and the cell may have co-evolved with miR-122 [27]. TRBP and Dicer may be recruited to the TAR RNA, to the Rev response element (RRE) RNA, to the virus-encoded (v)siRNA, or to other dsRNA parts of the entering virus to form ribonucleoprotein complexes. These complex formations would induce cleavage of dsRNA that would be beneficial for the virus. An argument against this hypothesis is the activity of vsiRNA, which is able to cleave the HIV envelope mRNA and inhibit virus replication when Tat is mutated [10]. In favor of this hypothesis is the positive activity of TRBP on HIV expression and replication, the ability of TRBP to bind TAR and RRE RNA, and the presence of short transcripts corresponding to the size of TAR RNA during viral infection. Although these transcripts likely stem from an ineffective transcription [28], it cannot be excluded that some are in fact generated by Dicer cleavage after TRBP binding to the $5^{\prime}$ or the $3^{\prime}$ TAR structure of the incoming virus. A large amount of TAR RNA in the cell inhibits PKR [29], and this may also be the case for other HIV small dsRNAs. This RNA-mediated inhibition would relieve the IFN innate immunity and favor virus replication. Alternatively, TRBP in RISC could favor the cleavage of cellular miRNAs that would favor HIV replication and the virus would have evolved in cells producing these RNAs. More studies on the relationship between the presence of short TAR RNAs and vsiRNAs, cellular miRNAs, the RNAi function and PKR activity during the viral replication cycle will be needed to evaluate this hypothesis (Fig. 2A).

2) Does HIV divert TRBP from Dicer to avoid cellular restriction by RNAi? If RNAi is a natural mechanism to restrict HIV replication, HIV must have developed mechanisms to guarantee effective replication. One mechanism is provided by Tat acting as an RNAi suppressor, but it may not be the only pathway. HIV may recruit TRBP and use it for its own benefit to avoid cleavage of its own RNA. TRBP on TAR and RRE RNAs is utilized by the virus to improve its own translation and replication and as a consequence becomes unavailable to bind Dicer and mediate RNAi. In this case, both TRBP and Tat would participate in the inhibition of HIV restriction by RNAi and act in concert to favor viral expression as shown earlier $[18,19,23]$, but by an additional mechanism. Studies on RNAi function and the levels of small RNAs during HIV replication should help to elucidate this hypothesis (Fig. 2B).

Whether HIV co-opts the RNAi pathway for its benefit or whether it diverts TRBP to avoid the cleavage of its RNA remains to be elucidated, but the end result is that the virus proceeds with replication. The final mechanism may come from studies in human cellular models in which the virus replicates poorly. Astrocytes represent such a model, but other models in which either the IFN response or the RNAi mechanism represents major cellular responses, will certainly emerge. TRBP, with its antagonistic properties as an anti-PKR and a pro-Dicer factor will be a key player in the balance between these mechanisms that will lead to viral replication or antiviral immunity.

\section{Competing interests}

The author(s) declare that they have no competing interests.

\section{Authors' contributions}

AG participated to the conception, design and writing of the article. SL participated in the interpretation of data and revision of the manuscript. GC participated in the interpretation of data and drawing of the figures.

\section{Acknowledgements}

We would like to thank Dr. D. Purcell, Dr. B. Berkhout, and the members of our laboratory for helpful discussions. The work done in our laboratory is/was supported by the Canadian Institutes of Health Research, the Canadian Foundation for AIDS Research, the Canadian Foundation for Innovation and the Fond de la Recherche en Santé du Québec. AG is the recipient of a Hugh \& Helen McPherson Memorial Award.

\section{References}

I. Ding SW, Li H, Lu R, Li F, Li WX: RNA silencing: a conserved antiviral immunity of plants and animals. Virus Res 2004, 102:109-115.

2. Karpala AJ, Doran TJ, Bean AG: Immune responses to dsRNA: implications for gene silencing technologies. Immunol Cell Biol 2005, 83:211-216.

3. Lecellier $\mathrm{CH}$, Voinnet $\mathrm{O}$ : RNA silencing: no mercy for viruses? Immunol Rev 2004, 198:285-303.

4. Lu R, Maduro M, Li F, Li HW, Broitman-Maduro G, Li WX, Ding SW: Animal virus replication and RNAi-mediated antiviral silencing in Caenorhabditis elegans. Nature 2005, 436: 1040-1043.

5. Mak J: RNA interference: more than a research tool in the vertebrates' adaptive immunity. Retrovirology 2005, 2:35.

6. Wilkins C, Dishongh R, Moore SC, Whitt MA, Chow M, Machaca K: RNA interference is an antiviral defence mechanism in Caenorhabditis elegans. Nature 2005, 436: I044-1047.

7. Colbère-Garapin F, Blondel B, Saulnier A, Pelletier I, Labadie K: Silencing viruses by RNA interference. Microbes Infect 2005, 7:767-775.

8. Haasnoot J, Cupac D, Berkhout B: Inhibition of virus replication by RNA interference. J Biomed Sci 2003, I0:607-616.

9. Pfeffer S, Zavolan M, Grasser FA, Chien M, Russo JJ, Ju J, John B, Enright AJ, Marks D, Sander C, Tuschl T: Identification of virusencoded microRNAs. Science 2004, 304:734-736.

10. Bennasser Y, Le SY, Benkirane M, Jeang KT: Evidence that HIV-I encodes an siRNA and a suppressor of RNA silencing. Immunity 2005, 22:607-619.

II. Lecellier CH, Dunoyer P, Arar K, Lehmann-Che J, Eyquem S, Himber C, Saib A, Voinnet O: A cellular microRNA mediates antiviral defense in human cells. Science 2005, 308:557-560.

12. Li WX, Li H, Lu R, Li F, Dus M, Atkinson P, Brydon EW, Johnson KL, Garcia-Sastre A, Ball LA, Palese P, Ding SW: Interferon antagonist proteins of influenza and vaccinia viruses are suppressors of RNA silencing. Proc Natl Acad Sci USA 2004, I 0 I : I 350- I 355.

13. Andersson MG, Haasnoot PC, Xu N, Berenjian S, Berkhout B, Akusjarvi G: Suppression of RNA interference by adenovirus virusassociated RNA. J Virol 2005, 79:9556-9565. 
14. Mouland AJ, Heveker N, Gatignol A: Virus-cell interactions. In Encyclopedia of Molecular Cell Biology and Molecular Medicine Volume 15. 2nd edition. Edited by: Meyers RA. Wiley-VCH Verlag, Germany; 2005:423-484.

15. Chendrimada TP, Gregory RI, Kumaraswamy E, Norman J, Cooch N, Nishikura K, Shiekhattar R: TRBP recruits the Dicer complex to Ago 2 for microRNA processing and gene silencing. Nature 2005, 436:740-744.

16. Haase AD, Jaskiewicz L, Zhang $H$, Lainé S, Sack R, Gatignol A, Filipowicz W: TRBP, a regulator of cellular PKR and HIV-I virus expression, interacts with Dicer and functions in RNA silencing. EMBO Rep 2005, 6:96I-967.

17. Ong CL, Thorpe JC, Gorry PR, Bannwarth S, Jaworowski A, Howard JL, Chung S, Campbell S, Christensen HS, Clerzius G, Mouland AJ, Gatignol A, Purcell DF: Low TRBP levels support an innate Human Immunodeficiency Virus type I resistance in astrocytes by enhancing the PKR antiviral response. J Virol 2005, 79: I2763-12772.

18. Gatignol A, Buckler-White A, Berkhout B, Jeang K-T: Characterization of a human TAR RNA-binding protein that activates the HIV-I LTR. Science 199|, 25 I:1597-|600.

19. Duarte M, Graham K, Daher A, Battisti P-L, Bannwarth S, Segeral E, Jeang K-T, Gatignol A: Characterization of TRBP I and TRBP2: stable stem-loop structure at the 5' end of TRBP2 mRNA resembles HIV-I TAR and is not found in its processed pseudogene. J Biomed Sci 2000, 7:494-506.

20. Daviet L, Erard M, Dorin D, Duarte M, Vaquero C, Gatignol A: The analysis of a binding difference between the two dsRNA binding domains in TRBP reveals the modular function of a KR-helix motif. Eur J Biochem 2000, 267:24I9-243I.

21. Gatignol A, Buckler C, Jeang K-T: Relatedness of an RNA binding motif in HIV-I TAR RNA binding protein TRBP to human PI/dsI kinase and Drosophila Staufen. Mol Cell Biol 1993, I 3:2193-2202

22. Benkirane M, Neuveut C, Chun RF, Smith SM, Samuel CE, Gatignol A, Jeang K-T: Oncogenic potential of TAR RNA-binding protein TRBP and its regulatory interaction with Protein Kinase PKR. EMBO J 1997, 16:61|-624.

23. Daher A, Longuet M, Dorin D, Bois F, Segeral E, Bannwarth S, Battisti P-L, Purcell D, Benarous R, Vaquero C, Meurs EF, Gatignol A: Two dimerization domains in the Trans-activation response RNA-binding Protein (TRBP) individually reverse the Protein Kinase $\mathbf{R}$ inhibition of HIV-I Long Terminal Repeat expression. J Biol Chem 200I, 276:33899-33905.

24. Park H, Davies MV, Langland JO, Chang H-W, Nam YS, Tartaglia J, Paoletti E, Jacobs BL, Kaufman RJ, Venkatesan S: TAR RNA-binding protein is an inhibitor of the interferon-induced protein kinase PKR. Proc Natl Acad Sci USA 1994, 91:47I3-47I7.

25. Dorin D, Bonnet MC, Bannwarth S, Gatignol A, Meurs EF, Vaquero C: The TAR RNA binding protein, TRBP, stimulates the expression of TAR-containing RNAs in vitro and in vivo independently of its ability to inhibit the dsRNA-dependent kinase PKR. J Biol Chem 2003, 278:4440-4448.

26. Bannwarth S, Talakoub L, Letourneur F, Duarte M, Purcell DF, Hiscott J, Gatignol A: Organization of the human tarbp2 gene reveals two promoters that are repressed in an astrocytic cell line. J Biol Chem 200I, 276:48803-488I3.

27. Jopling CL, Yi M, Lancaster AM, Lemon SM, Sarnow P: Modulation of hepatitis $C$ virus RNA abundance by a liver-specific MicroRNA. Science 2005, 309:|577-158I.

28. Sheldon M, Ratnasabapathy R, Hernandez N: Characterization of the inducer of short transcripts, a human immunodeficiency virus type I transcriptional element that activates the synthesis of short RNAs. Mol Cell Biol 1993, I3:|25|-1263.

29. Gunnery S, Rice AP, Robertson HD, Mathews MB: Tat-responsive region RNA of human immunodeficiency virus I can prevent activation of the double-stranded-RNA-activated protein kinase. Proc Natl Acad Sci USA 1990, 87:8687-869l.

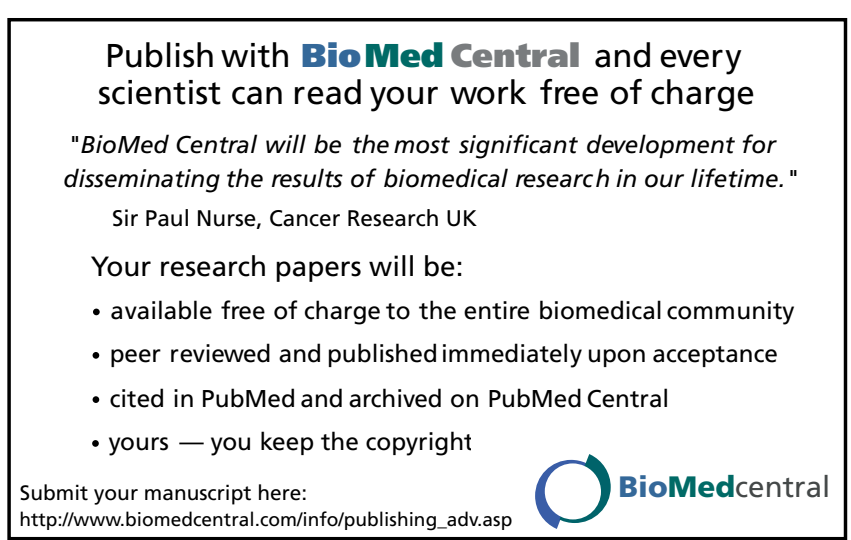


Publish with Bio Med Central and every scientist can read your work free of charge

"BioMed Central will be the most significant development for disseminating the results of biomedical research in our lifetime. " Sir Paul Nurse, Cancer Research UK

Your research papers will be:

- available free of charge to the entire biomedical community

- peer reviewed and published immediately upon acceptance

- cited in PubMed and archived on PubMed Central

- yours - you keep the copyright 